\title{
Selecting Networks of Reserves to Maximise Biological Diversity
}

\section{R. Margules, A. 0. Nicholls}

CSIRO Division of Wildlife and Rangelands Research, PO Box 84.

Lyncham. ACT 2602. Australia

\section{R. L. Pressey}

New South Wales National Parks and Wildlife Service. PO Box N189, Grosvenor Street. Sydney, NSW 2000, Australia

Received 4 July 1987; revised version received 6 August 1987: accepted 7 August 19871

\section{A BSTRACT}

A prerequisite for preserving maximum biological diversity in a given biological domain is to identify a reserve network which includes every possible species. Two algorithms are presented which define the smallest number of wetlands on the Macteay Valley floodplain, Australia. which include all of the wetland plant species. One of these algorithms maximises species richness. The other is constrained to ensure each of nine weiland types is represented. as well as all species.

To represent every plant species at least once. only $4.6 \%$ of the total number of wetlands is reguired, but they constitute $44.9 \%$ of the total wetland area. In order to represent all types of wetlands, as well as all plant species. $75.3 \%$ of the total wetland area is required. The results can be constrained to achieve other conservation goals such as preserving naluralnessi rarity population size, efc.. by imposing conditions on rules within the algorithms. In this way a reserve network chosen to maximise diversity can be manipulated to optimise other conservation values.

Biol. Conserv. 0006-3207/88/505:50 i Elsevier Applied Science Publishers Ltd. England. 1988. Printed in Great Britain 


\section{INTRODUCTION}

The criteria used to judge conservation value are many and varied. In a review of conservation evaluation schemes, Margules \& Usher (1981) recognised 18 classes of criteria, eight of which were seen as scientific. Evaluation schemes generally attempt to combine criteria in some way, either subjectively (e.g. Ratcliffe, 1977) or via a numerical index (e.g. Wright, 1977). People weight different criteria in many different ways and finding agreement on any given conservation assessment (excluding sites of the very highest value) or on any index for assessment, is unlikely (Margules, 1984, 1986). The most widely used scientific criteria, diversity, rarity, naturalness, size and representativeness, have been discussed in detail recently by Margules (1986) and Usher (1986). All refer, either wholly or in part, to a common underlying theme: the maintenance of biological diversity in perpetuity. If it were possible to identify a minimum set of sites which encompassed maximum biological diversity in a given region, there might at least be some agreement that their conservation significance was high. Sites meeting any other criteria deemed appropriate could then be added to the list, but the smallest number necessary for maximum diversity would be defined.

The identification of a set of sites which maximise diversity is an essential prerequisite for conservation evaluation that seems to have been forgotten in much of the recent literature on reserve design and selection. For example, the goal of maintaining maximum biological diversity is implicit in the entrenched debate on the design of nature reserves (e.g. Diamond, 1975; Simberloff \& Abele, 1976, 1982; Higgs \& Usher, 1980; Diamond \& May, 1981; Higgs, 1981; Margules et al., 1982). But that debate is concerned mainly with ecological processes within reserves, so even reliable reserve design principles will not preserve maximum diversity if maximum diversity has not been set aside in the first place.

In this paper we consider how to select the smallest number of sites from some biological domain which represents all, or as many as possible, of the species in that domain. Conceptually, our approach is similar to those of Kirkpatrick (1983) and Kirkpatrick \& Harwood (1983) but we have not weighted species at this stage and our algorithms, whilst still heuristic, are more likely to lead to the smallest number of sites representing all species We use as an example the wetlands of the Macleay Valley floodplain in coastal northern New South Wales, Australia, where complete lists of plant species from every wetland were available. Our main purpose is to presen and contrast algorithms which optimise different concepts of biological diversity. The results allow a re-evaluation of ideas about how much land or how many reserves should be set aside to preserve biological diversity.

\section{MACLEAY VALLEY WETLANDS}

All higher plant species present in all 432 wetlands of the Macleay Valley floodplain were recorded; there were 118 species, 98 of which are native to the region (Pressey, 1984). The wetlands were identified and delineated by the presence of plants adapted to waterlogging. All the wetlands are lentic waterbodies which are seasonally or permanently inundated.

Using these data we set out explicit numerical procedures to identify sets of wetlands which satisfy two different approaches to maximising biological diversity. The first is that each species should be represented in the chosen set of wetlands at least a minimum number of times. The second is that each wetland type, defined in terms of the similarity of species complements (Austin \& Margules, 1986), should be represented at least once in a set of wetlands that also includes each species at least once.

\section{SPECIES REPRESENTATION}

\section{Algorithm}

A numerical algorithm was used to identify the minimum set of wetlands in which all 98 native species are represented at least once. The procedure then was extended to find the smallest set of wetlands in which all species (except those occurring only once) are represented twice, the set in which all species (except those occurring only once or twice) are represented three times, and so on up to five times. The algorithm for selecting the set of wetlands in which all species occur at least once consisted of the following rules:

I. Select all wetlands with any species which occur only once.

2. Starting with the rarest (i.e. the least frequent species in the data matrix) unrepresented species, select from all wetlands on which it occurs, the wetland contributing the maximum number of additional (i.e. unrepresented) species.

3. Where two or more wetlands contribute an equal number of additional species, select the wetland with the least frequent group of species. The least frequent group was defined as that group having the smallest sum of frequencies of occurrence in the remaining unselected wetlands.

4. Where two or more wetlands contribute an equal number of infrequent species, select the first wetland encountered.

The fourth step, where it is necessary, is order-dependent. It would be possible at that stage to separate equally qualified wetlands by introducing 
other rules, but they would embody new concepts. For example, we could select the wetland with the least number of exotics, but that introduces the criterion of naturalness. Our purpose in this paper is to reiterate the principle that reserves can be selected to maximise diversity in the first place, and to contrast the results of using different concepts of biological diversity. The introduction of other criteria would be appropriate, even necessary, in a real conservation evaluation exercise, and will be considered in forthcoming papers on applications of the algorithms presented here.

To obtain a minimum set of wetlands that represent as many of the species that it is possible to represent twice, three times, or more, the algorithm needs to be modified. Rule 1 beomes: Select all wetlands which contain species which have a frequency in the data matrix less than, or equal to, the required level of representation. Rule 2 is changed to: Select from the currently unselected wetlands on which the next rarest under-represented species was recorded that wetland which will add the most additional species or add most to the representation of those currently under-represented. Rules 3 and 4 remain the same. The minimum set required to represent every species at least once is not necessarily a sub-set of that required for two or more representations of all possible species.

\section{Results}

Table 1 gives the number of wetlands required to represent each species once, and where possible, twice, three times, four times and five times. Rule 1 of the algorithm, to select the minimum set of wetlands needed to represent every species at least once, resulted in 15 wetlands being selected with 87 species represented. A further five wetlands were needed to represent the remaining 11 species, making a total of 20 wetlands required to represent each species at least once. The number required to represent all possible

\section{TABLE}

A Summary of the Results Showing the Number of Wetlands Needed to Represent each Species I, 2 3, 4 and 5 times

\begin{tabular}{ccc}
\hline \multirow{2}{*}{ Number of representations } & \multicolumn{2}{c}{ Number of wetlands } \\
\cline { 2 - 3 } & Rule I & Total \\
\hline & 15 & 20 \\
2 & 23 & 31 \\
3 & 28 & 40 \\
4 & 36 & 52 \\
5 & 43 & 65 \\
\hline
\end{tabular}

(1)

-20
10

Fig. 1. A species-area plot showing the wetlands required to represent every species at leas once (1) and the extra wetlands needed to represent all possible species twice (2), three times (3), four times (4) and five times (5). The dots represent wetlands not included in the sets needed to represent all species once, twice, three, four or five times. The regression line, the average species-area line, represents the function $\log$ (species number) $2-275+0 \cdot 110 \log ($ area $)+$ $0-009[\log (2 \mathrm{are} .21]$. The numbers in parentheses are the numbers of the three largest wetlands $0-009[\log (a r e x)]$. The numbers in parentheses are the number
referred to in Fig. 2.

species twice is 31 and it increases steadily to 65 for all possible species five times.

Figure 1 is a species - area plot of the wetlands showing the relationship of the 20 selected wetlands with the remainder. Also plotted is the average species - area line from the equation;

$$
\log S=a+b \log (\operatorname{area})+\mathrm{c}[\log (\operatorname{area})]^{2}
$$

All but one of the wetlands selected to represent each species at least once fall above the average line: they are more species-rich wetlands per unit area than average. This means there are no small, species-poor wetlands with unique species on them. As more and more representations are required. the proportion of species-poor wetlands increases.

Figure 2 shows the frequency with which species that are rare in this data set occur on the three largest wetlands. Wetland 353 was included in the group to represent each species once because it had three unique species. Wetland 69 was included because, although it has no unique species, it has a species (one of two, Fig. 2) that occurs in only two wetlands and when 


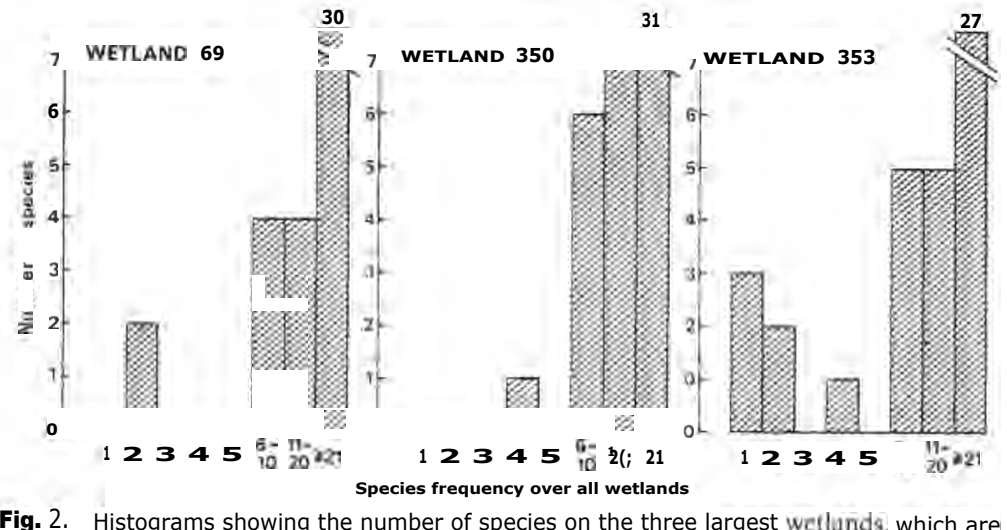

Fig. 2. Histograms showing the number of species on the three largest wetlunds. which are infrequent in the whole data matrix.

compared with the other wetland that has that same species (wetland 63) it contributed four unrepresented species as opposed to the two unrepresented species which wetland 63 could contribute (step 2 of the algorithm). Wetland 350 is the largest wetland. but the least frequent species on wetland 350 also occurs on three other wetlands. One of those three also included a unique species, so wetland 350 was not included in the set of wetlands required to represent all species at least once. As it turned out wetland 350, the second richest in species as well as the largest, was not included until four representations of each species were required because it has no unique species and few uncommon ones.

\section{HABITAT REPRESENTATION}

The concept of habitat representation is based on the idea that, by conserving all habitats, the maximum number of species will be represented. including species not used to define the habitats-in this case, species other than higher plants.

Using the lists of plant species as attributes, the wetlands were classified by an hierarchical agglomerative method (Sneath \& Sokal, 1973; Clifford \& Stephenson, 1975). Association between wetlands (similarity) was measured with the Bray-Curtis association measure (Bray \& Curtis, 1957) because it does not weight species number. We did not want species-rich or speciespoor wetlands grouped together unless their species complements were similar. We used a weighted pair group arithmetic averaging fusion strategy (Sneath \& Sokal, 1973). The classification was stopped at the nine group level. The decision on where to stop a classification is always somewhat arbitrary. Nine groups seemed logical because below this level small changes in the coefficient of association produced new groups, and above this level, a single very large, relatively heterogeneous group was formed. In keeping with our concept of maximum species representation, we chose to adopt a procedure which ensured that every species was represented at least once, as well as ensuring that each wetland type was represented at least once.

\section{Algorithm}

The algorithm had the following steps:

1. Select the wetland from each habitat type which has the greatest number of plant species. If all species are included, then stop.

Select a second wetland from each type which adds the most new species. A habitat type will be passed over if there are no wetlands from that type which add new species. If all species are included then stop.

3. Continue to select a third or fourth, etc., from each habitat type which adds the most new species. or pass over a type when no wetlands from that type add new species, until all species are represented.

There is an order dependence beginning at the second step because the first habitat type examined in each step from then on might add species also occurring in other habitat types, but the relevant wetlands from those other types will not be selected, simply because they were not examined first. The reverse order of selection. $9.8,7 \ldots . .3,2,1$, was tried also, as well as two random orders, $9,2,8,4,3.1,5,7,6$ and $2,7,3,9,8,6,5,1,4$, to examine the influence of order dependence.

\section{Results}

Table 2 shows the number of wetlands and the number of species selected at each step of this algorithm, with wetland types in the order 1 to 9 . After the first step, all nine habitat types were represented but only 68 species were included. The second step added 12 species and six wetlands. A further six passes were required to include all species in a total of 29 wetlands. Table 3 is a summary of the results of all four starting points. Order 1 to 9 required 29 wetlands whilst the other three orders required 30 . Of the 29 or 30 wetlands, 27 were common to all selections. The remaining two or three needed to complete each set were selected from five wetlands. The frequency of 
TABLE 2

Selection of a Minimum Set of Wetlands to Maximise Habitat Representation Whilst Ensuring each Species is Represented at Least Once

\begin{tabular}{ccc}
\hline Step & Number of wetlands & Number of species \\
\hline & 9 & 68 \\
2 & 15 & 80 \\
3 & 19 & 87 \\
4 & 23 & 92 \\
5 & 25 & 94 \\
6 & 27 & 96 \\
7 & 28 & 97 \\
8 & 29 & 98 \\
\hline
\end{tabular}

representation of each wetland type is very similar in Table 3 , regardless of order. The initial selection of nine wetlands each time (one from each habitat type) does not include, in the list of species represented, any species with an overall frequency of 3 or less. The number of new species added at each step of the algorithm declines as follows: $68,12,7,5,2,2,1,1$. The average number of new species per wetland declines in a similar manner: 7-6, 2, F8, 1.3, 1, 1, 1, 1 . Thus, additional species added after the first step become increasingly expensive in terms of the number of wetlands needed to conserve them.

It is possible to compare results from the habitat representation algorithm with results from the species representation algorithm. Of the 20 wetlands required to represent every species at least once, 18 are in the list of 29 needed

TABLE 3

The Number of Times each Wetland Type is Represented in the Selection Using the Four Different Orders Listed in the Text

\begin{tabular}{ccccc}
\hline \multirow{2}{*}{$\begin{array}{c}\text { Wetland } \\
\text { type }\end{array}$} & \multicolumn{4}{c}{ Total number of wetlands } \\
\cline { 2 - 5 } & Order 1-9 & Order 9-1 & Random 1 & Random 2 \\
\hline & 8 & 8 & 8 & 8 \\
2 & 4 & 4 & 4 & 4 \\
3 & 2 & 2 & 2 & 2 \\
4 & 6 & 6 & 6 & 6 \\
5 & 4 & 4 & 4 & 4 \\
6 & 2 & 2 & 2 & 2 \\
7 & & 2 & 2 & 1 \\
8 & & 30 & 30 & 30 \\
9 & 29 & & & \\
Total & & & & \\
\hline
\end{tabular}

TABLE 4

The Proportion of Wetlands Represented by Each of the Different Minimum Sets Calculated, and the Corresponding Proportion of Total Wetland Area

\begin{tabular}{lcc}
\hline Conservation goal & $\begin{array}{c}\text { Number of wetlands } \\
(\%)\end{array}$ & $\begin{array}{c}\text { Area of wetlands } \\
(\%)\end{array}$ \\
\hline All species at least once & 4.6 & 44.9 \\
All species at least twice & 7.2 & 45.4 \\
All species at least 3 x & 9.3 & 45.7 \\
All species at least 4 x & 12.0 & 77.1 \\
All species at least 5 x & 15.0 & 78.5 \\
All species at least once & & 75.3 \\
plus all wetland types & 6.7 & \\
\hline
\end{tabular}

to represent each habitat as well as every species once. However, only four of the nine wetland types are represented by those 18 . The five wetland types which are represented only once or twice in all results from Table 3 are missing-i.e. types 3, 5,7, 8 and 9. This is because types 3, 5, 7, 8 and 9 are species-poor relative to the other four types. Both algorithms favour the selection of species-rich sites because rich sites more often provide the most new species, the main criterion for admission to the list.

Table 4 shows the percentage of wetlands, and the percentage of total wetland area which they occupy, needed to satisfy each algorithm. Multiple representation of species might be desirable, especially in wetlands where the persistence of species is so susceptible to physical dynamics such as water level changes. However, representing each species more than three times increases the area of wetland required by $31.4 \%$.

\section{DISCUSSION}

We recognise that many decisions on the allocation of land for nature conservation are made on pragmatic rather than scientific grounds. These include low primary production potential, inaccessibility, availability, public and political perceptions, etc. For related reasons, it will be difficult or impossible to conserve all species in reserve networks. However, the belief that biological diversity is 'reasonably secure' or 'as well taken care of as possible' with the dedication of one or a few well chosen reserves in an ecological domain is unfounded. The reality is that a very large number of reserves seems necessary to secure biological diversity.

The smallest number of wetlands required to meet any of the concepts of representation was 20 , but this increased rapidly when more than one population was required (Table 1), and rose to 29 when it was necessary to 
represent all different wetland types as well as all species at least once. Figures of $5 \%$ or $10 \%$ are often heard of as desirable minimum proportions of the land surface that should be dedicated to nature conservation and although they may not be given credit widely among conservationists, they have found their way through to politicians and other decision makers. So how large an area is required? Table 4 shows that $5 \%$ or even $10 \%$ of the wetland area would be hopelessly inadequate, even for representation of al species once, which requires only $4.6 \%$ of the wetlands, but those wetlands represent $449 \%$ of the total wetland area. Multiple representations would guard against extinctions due to species turnover, especially on wetlands, which are subjected to drastic changes in physical conditions such as wate depth - though species in other kinds of habitat patches also may be at risk Janzen (1986) has argued eloquently that many species regarded as secure in reserves in the tropics are, in fact, endangered. Cumulative local extinction in isolated reserves may lead to species extinctions. For these Macleay Valley wetlands, representation three times requires little more area than representation once. The jump to four times or more, however. increases the area required by nearly one third. In a similar exercise using remnant mallee (a multi-stemmed eucalypt growth form) patches on the Eyre Peninsula in South Australia, where it was necessary to estimate probabilities of occurrence in unsampled patches with statistical models relating species presences to environmental variables, we found that 12 patches out of a total of 101 (approximately 12\%) was the smallest number with a 95\% chance of representing each of six plant communities at least once. To have a $95 \%$ chance of representing every community five times we would need 45 , nearly half (Margules \& Nicholls, 1987). If this result is found in many other situations, any hope of maintaining biological diversity in the face of competing land uses looks forlorn.

The range of options available in conservation evaluation and the number of decisions which have to be made, often implicitly, was illustrated when a decision on separating equally qualified wetlands had to be made and the choice was order-dependent. Two obvious alternatives were to choose the wetland with the fewest exotics, or, because there is a strong positive correlation between wetland size and population size, the largest. though that would increase the already large total area required. The choice of which criterion to introduce at this stage is subjective, but by being forced into making an explicit decision within the framework of a numerical algorithm, the evaluation process is made clear to both the evaluator and those affected by the evaluation. We have side-stepped the problem of introducing new rules (criteria of conservation value) here because we wanted to contrast concepts of diversity and to publicise the explicit algorithmic approach. However, it is easy to make the procedure multi- objective by imposing conditions on rules. A simple example could involve, say, a rare species which it was desirable to represent by at least five populations. We could then ask the question 'What is the smallest set of wetlands which has every species in it at least once, and species x, five times?'. Another approach might be to attempt to minimise the possibility of local extinction by asking for the largest population of each species, assuming data on abundance are available. If re-colonisation following local extinction proves to be a significant factor in maintaining diversity in islandlike reserve networks, then proximity could be built in as a constraint. At either step 2 or 3 of the species representation algorithm, for example, the rule could be to select the site adding the most new species within a set distance of the sites selected already. Any conceivable constraint or combination of constraints is possible and different constraints will be appropriate in different circumstances.

For habitat representation, the additional requirement of representing all species means that the inclusion of the last few species adds a disproportionate number of wetlands. Table 2 shows that 68 species are represented in nine wetlands and that a further 20 wetlands were needed to encompass the remaining 30 . The last six wetlands to be added add only six species, raising the possibility of reducing the number of wetlands required by sacrificing, say, six species. An extra-regional context would be necessary to judge the significance of these species, e.g. whether they were reserved elsewhere, whether they are rare, erc.. to determine whether they could be discarded for the purpose of reserve selection on the Macleay Valley floodplain. Kirkpatrick \& Harwood (1983) take just such an approach in evaluating Tasmanian wetlands. They identified unreserved species and then located the minimum number of wetlands necessary to ensure that each species was reserved at least once. Their search began with the richest wetland, i.e. the one with the most unreserved species, and added wetlands which added the most new unreserved species until all species were reserved. Using this approach. wetlands with unique species tend to be added late in the selection procedure, and as is the case above, add a disproportionate number of wetlands. With limited resources for nature conservation, compromises will have to be made and by commencing with the riches wetland and adding wetlands that add the most new species, at any point in the process the number of species on the wetlands chosen to that stage is maximised. However, species with unique occurrences may not be included until towards the end of the procedure, so stopping anywhere before the end will ignore some species, including the very rare ones. The alternative approach we adopted here, of starting with wetlands with unique species (algorithm 1), ensures that rare species are included, in a smaller number of wetlands than could be obtained using the Kirkpatrick \& Harwood (1983) 
procedure. We searched for the smallest number of wetlands that represented all species, regardless of their status outside our domain of interest. However, judgments on the significance of species, either high or low, can be incorporated as constraints to the search, as described above. Value judgments are still necessary and no doubt always will be, but by using the approach advocated here, the extent of any possible trade-off between maximising diversity and preserving rare species is made clear.

The wetlands used in this study were all equally well known: there was a complete list of plant species for every wetland. Most data sets collected in most parts of the world for use in conservation evaluation represent a sample of all possible sites (wetlands, habitat patches, etc.) of interest Similarly, even in biologically well-known parts of the world, many species such as invertebrates are known from only a sub-set of sites. In such cases. one approach would be to estimate probabilities of species occurrence in unsampled sites and analyse this matrix of probabilities of species occurrence rather than a presence/absence matrix, as was done here. The methodology for such an approach is described in the paper by Margules \& Nicholls (1987) referred to above. We used logistic regression analysis to predict the probabilities of plant communities occurring in unsampled habitat patches in a region of croplands in South Australia, from a subset of sampled patches, using a small set of environmental variables as predictors. This approach is being refined and field tested in the wheat belt of New South Wales.

This has been a study in selecting a minimum set of sites to be representative of some biological domain, using the idea that maximum biological diversity will be maintained best by representing the maximum number of species in reserve networks. Different concepts of representation led to different results, highlighting the problems of trying to provide ecologically sensible answers to questions being asked of conservationists such as 'what is the preferred network of nature reserves in this region?' or 'how well is this biological domain represented in the existing reserve network?' Whilst it is still impossible to answer such questions unequivocally, we have shown how to identify a small number of options, any one of which might provide a sound basis for building a reserve network. Anything less will not secure maximum biological diversity.

\section{ACKNOWLEDGEMENTS}

Mike Austin and Graham Yapp commented critically on the manuscript. Mike Austin also suggested the habitat analysis.

\section{REFERENCES}

Adams, M. W. \& Rose, C. 1. (1978). The selection of reserves for conservation. University College, London, Discussion Papers in Conservation, No. 20.

Austin. M. P. \& Margules, C. R. (1986). Assessing representativeness. In Wildlife conservation evaluation, ed. by M. B. Usher, 45-67. London, Chapman and Hall.

Bray, J. R. \& Curtis, J. T. (1957). An ordination of the upland forest communities of Southern Wisconsin. Ecol. Monogr., 27, 325-49.

Clifford, H. T. \& Stephenson. W. (1975). An introduction to numerical classification New York, Academic Press.

Diamond. J. M. (1975). The island dilemma: Lessons of modern biogeographic studies for the design of nature reserves. Biol. Conserv., 7,129-46.

Diamond J. M. \& May, R. M. (1981). Island biogeography and the design of natural reserves. In Theoretical ecology: Principles and applications, ed.by R. M. May. 2nd edn, 163-86. Oxford. Blackwell.

Higgs. A. J. (1981). Island biogeography and nature reserve design. J. Biogeogr.. 8. $117-24$

Higgs, A. J. \& Usher, M. B. (1980). Should nature reserves be large or small? Nature. Lond. 285, 568-9.

Janzen. D. H. (1986). Blurry catastrophes. Oikos, 47, 1-2

'"' Kirkpatrick J. B. (1983). An iterative method for establishing priorities for the selection of nature reserves: An example from Tasmania. Biol. Conserv., 25. selection
$127-34$.

Kirkpatrick, J. B. \& Harwood. C. E. (1983). Conservation of Tasmanian macrophyte wetland vegetation. Pap. Proc. R. Soc. Tasmania, 117, 5-20.

Vargules. C. R. (1984). Conservation evaluation in practice. II. Enclosed grasslands in the Yorkshire Dales. Great Britain. J. Environ. Marrage, 18. 169-83.

Marvules, C. R. (1986). Conservation evaluation in practice. In Wildlife conservation evuluetion ed. by M. B. Usher, 297-314. London, Chapman and Hall

Margules, C. R. \& Nicholls, A. o. (1987). Assessing the conservation value of remnant habitat 'islands': Mallee patches on the western Eyre Peninsula, South Australia. In Nature conservation: the role of remnants of native vegetation, ed. by D. A. Saunders, G. W. Arnold. A. A. Burbidge and A. J. M. Hopkins, 89-102. Sydney, Surrey Beatty and Sons Pty Ltd in association with CSIRO and CALM.

Margules, C. R. \& Usher. M. B. (1981). Criteria used in assessing wildlife conservation potential: A review. Biol. Conserv.. 21, 79-109.

Maruules. C. R., Higgs, A. J. \& Rafe. R. W. (1982). Modern biogeographic theory: Are there any lessons for nature reserve design? Biol. Conserv.. 24. 115-28.

Pressey. R. L. (1984). A surve' of wetlands on the lower Macleay floodplain. New South Wales. Sydney, New South Wales National Parks and Wildlife Service (Unpublished report).

Ratclifie. D. A. (1977). A nature conservation review. 2 vols. Cambridge, Cambridee University Press.

Simberloff, D. S. \& Abele, L. G. (1976). Island biogeography theory and conservation practice. Science, N.Y., I9I. 285-6.

Simberloff, D. S. \& Abele, L. G. (1982). Refuge design and island biogeographic theory: Effects of fragmentation. Am. Nat., 120, 41-50. 
Sneath, P. H. \& Sokal, R. R. (1973). Numerical taxonomy. San Francisco, W. H. Freeman and Company.

Usher, M. B. (1986). Wildlife conservation evaluation: Attributes, criteria and values. In Wildlife conservation evaluation, ed. by M. B. Usher, 3-44. London, Chapman and Hall.

right, D. F. (1977). A site evaluation scheme for use in the assessment of potential nature reserves. Biol. Conserv., 11, 293-305.

\section{Book Reviews}

Deforestation in Uganda. By A. C. Hamilton. Oxford University Press with East African Wildlife Society. 1984.92 pp.

Uganda has, for a long period of time. had reserved some 570000 hectares of moist tropical forest which represents only about $3 \%$ of the land area of the country but produced almost all the industrial wood used in the country. In addition it has had about 500000 ha of natural forest reserves on some of the mountains which were retained as protection reserves for soil conservation. Both were valuable in conserving genetic resources of both animals and plants and in preserving some of the last natural forest habitats in East Africa and the transition in flora and fauna between West and East Africa Many of the reserves were small with large lengths of boundary for quite small areas of forest and were surrounded by quite densely populated settled agriculture. Much forest or semi-forest used to exist on non-reserved land but over the years this has decreased drastically. Dr Hamilton describes the situation in Uganda after about ten years of increasing civil strife and maladministration and, latterly, a severe dearth of funds to protect or manage the forest.

The book is divided into chapters covering: the deforestation problem in Uganda; the Ugandan background: environmental trends; the forests: trees climate and water; forestry in Uganda 1898-1972; forestry in Uganda 1972-1982 and the future of forestry.

In spite of the problems of getting detailed and reliable information on the state of the forests, the author has accumulated a considerable quantity of useful information which is clearly and logically presented to make a strong

Biol. Conserv. 43(1988)— Elsevier Applied Science Publishers Ltd. England. 1988. Printed in Great Britain 